Жеблиенок Наталья Николаевна (Санкт-Петербург). Кандидат архитектуры, доцент, советник РААСН. Главный градостроитель проектов 000 «Лаборатории градопланирования им. М.Л. Петровича» (190013, Санкт-Петербург, наб. реки Фонтанки, 108, б/ц «Фонтанка 108», офис 1). Эл. почта: shesternevann@gmail.com.

Zheblienok Natalya N. (St. Petersburg). Candidate of Architecture, Associate Professor, Advisor of RAACS. Chief Urban Planner of Projects at the M.L. Petrovich Laboratory of Urban Planning (108 Fontanka river emb., office 1, Saint Petersburg, 190013. Laboratory of Urban Planning). E-mail: shesternevann@gmail.com.

๑ Жеблиенок Н.Н., 2021. Academia. Архитектура и строительство, № 4, стр. 80-85.

\title{
Экосистемы градостроительства в постсоциалистическом контексте. Часть 2. «Отставание», становящееся «лидерством»")
}

\author{
Н.Н.Жеблиенок, Лаборатория градопланирования, Санкт-Петербург
}

За последние десятилетия Польша, Венгрия, Сербия, Чешская Республика, Болгария существенно преобразили собственные градостроительные отрасли, сохранив при этом часть социалистического наследия. Системы профессионального образования наиболее консервативны: отдельные учебные заведения в индивидуальном порядке дополняют учебные планы, но в целом сохраняется приверженность архитектурной модели. Системы градостроительной деятельности оцениваются как сохраняющие черты социалистического периода (несмотря на то, что «были созданы новые рамки для профессиональных действий, основные предпосылки для работы новой системы планирования отсутствовали, и изменений в реальной практике городского планирования не произошло» [1]). Активно развиваются системы градостроительных знаний за счёт ультрасовременных тематических исследований (социализация градостроительства, бюджетирование проектов совместного планирования, градостроительная педагогика, инфраструктурный урбанизм и др.).

Польща. Варшавский технологический университет и Гданьский технологический университет (Politechnika Gdańska) предлагают в рамках архитектурных программ «развивать навыки, связанные с формированием урбанизированных территорий... коммунальных объектов... и пространственных городских проектов ${ }^{1} »$. Эти учебные заведения инженерно-ориентированы, их программы формально относятся к архитектурной модели, по сути будучи наполнены техническими, экологическими, ландшафтными дисциплинами [2]. В Гданьском технологическом реализуются инновационные подходы для развития коммуникационных навыков, подготовки к публичным дебатам в области градостроительства [2]. Реализуется стандарт образовательной среды, в которой инженеры, архитекторы, планировщики и программисты ${ }^{2}$ обучаются совместно. Университетский (в противоположность узкоотраслевому, характерному для социалистического периода) тип передачи знаний обуславливает переход к новой парадигме гуманитарно-ориентированного профессионального мышления ${ }^{3}$. Научный дискурс отличает фокус на гуманитарный потенциал градостроительства; подробно исследованы темы «этики и профессионального мышления в градостроительстве» [3], «компетентности местных сообществ» и «инфраструктурного урбанизма» [2]. С точки зрения традиционной трактовки профессии «градостроителя» польский опыт [4] идентичен опыту, например, Республики Молдовы или Латвийской Республики. Ключевые отличия связаны с активной позицией профессионального сообщества по отношению к разветвлению профессии в интересах существенно более широкой применимости градостроительных знаний (в науке, пространственном планировании, работе с местными сообществами, разработке и координации документации, просветительской работе с населением [5]). Архитектор «градостроительного профиля» (в европейском «планировочном» понимании этого термина),

\footnotetext{
*) Продолжение. Первая часть статьи «Экосистемы градостроительства в постсоциалистическом контексте. Часть 1. Бывшие советские республики: между "архитектурой" и "планировкой"» опубликована в №3 журнала «Аcademia. Архитектура и строительство» за этот год. Работа выполнена в рамках Плана фундаментальных научных исследований Минстроя России и РААСН на 2021 год, тема № 2211 «Формирование профессионального института современного градостроительства в разных странах мира» (рук. - акад., проф. д-р арх. Бочаров Ю.П.).

${ }^{1}$ https://www.bachelorstudies.com/Bachelor-of-Science-in-Architecture/Poland/Gda\%C5\%84sk-University-of-Technology/.

${ }^{2}$ Так, в Познанском технологическом университете бакалаврская программа по архитектуре, устойчивым строительным технологиям (Sustainable Building Engineering) содержательно является программой подготовки градостроителей, которая реализуется параллельно с программами в области химических технологий, инженерного менеджмента, робототехники (см. https://www.masterstudies.com/universities/Poland/PUT/?pk_vid=985152087edad5e91626294371c6625b).

${ }^{3}$ Открываются и полностью самостоятельные образовательные учреждения градостроительного профиля, как, например, «School of the Built Environment, Spatial Policy and City and Regional Management» в городе Лодзи.
} 
дополнен специалистами «городского консультирования» (англ. - urban coaching), эколого-инфраструктурным профилем «инфраструктурный урбанизм», обсуждается ролевая модель «градостроитель-модератор» (англ. - an urban planner-moderator) [2]. Развертывается система городского наставничества (англ. - urban mentoring [6]), внедряются основы градостроительной педагогики, созданы правовые механизмы для доступа к процессам проектирования только при наличии практического опыта в планировании, а не только соответствующего образования [4]. Институт градостроительства в Польше развивается, в большей степени, за счёт прироста инновационных форм градостроительной деятельности и новых научных направлений.

Словакия и Венгрия. Градостроительные вопросы в этих странах тотально делегированы архитектурным факультетам. Так, Факультет архитектуры и дизайна Словацкого технологического университета в Братиславе предлагает магистерскую программу обучения архитектуре, в результате которой выпускник получает степень «инженер-архитектор» ${ }^{4}$, что даёт ему возможность, «... работая в масштабе города... разраба-

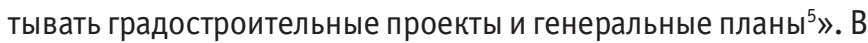
Печском университете (University of Pécs) по программе «Apхитектура» студентов обучают применять свои комплексные знания в области архитектуры и городского планирования, а также в многогранной области формирования окружающей среды в целом ${ }^{6}$.

Сербия. Социальные реформы, затронувшие градостроительство, начались в Сербии после 2000-х годов (по причине гражданской войны 1990-х), так что интересующие нас трансформации находятся в несколько иной фазе, нежели в других странах. Научный дискурс о состоянии сербского института профессии в градостроительстве (и шире - в отношении градостроительных дисциплин, потенциала применения градостроительных исследований) развит на очень высоком уровне. Состояние сербской системы градостроительной деятельности оценивается как неудовлетворительное (низкое качество профессиональной документации, сохранение «архитектурной модели» в подготовке градостроителей [1]), по мнению учёных, профессия в целом не смогла найти свой путь. Имеют место прорывные исследования: создание коммуникационных платформ для выстраивания диалога между профессионалами и местными сообществами посредством введения нового института - профессионального наставничества [1], в градостроительной педагогике [1], поисках альтернативных методов для информирования местных сообществ [7]. В Сербии разработана и внедрена магистерская программа для архитекторов (master's course of study in Integrated Urbanism), которая представляет собой административно-организационный профиль градостроительного образования. Программа сфокусирована на трансдисциплинарных практиках и коммуникативных навыках, выдвигая на профессиональный рынок новое действующее лицо - консультанта/администратора по внедрению программ устойчивого пространственного развития территорий [1].

Выявленные данные позволяют сформулировать типологию «моделей специалиста» в сфере градостроительства (табл. 2):

- Тип 1: «архитектор-планировщик» - профессионал со специализацией в области планировки; «градостроительство» преподаётся как одна из дисциплин. Нацелен на формирова-

\footnotetext{
${ }^{4}$ Дословно «degree of “Ing. arch." (Engineer architect)».

${ }^{5}$ https://www.masterstudies.com/M.Sc.-in-Architecture/Slovakia/FAD-STU/.

${ }^{6}$ https://www.bachelorstudies.com/BSc-MSc-in-Architecture/Hungary/University-of-P\%C3\%A9cs/.
}

Таблица 2. Основные модели развития профессии градостроителя в рассматриваемых странах

\begin{tabular}{|c|c|c|c|}
\hline $\begin{array}{c}\text { Условно выделенная } \\
\text { модель }\end{array}$ & $\begin{array}{c}\text { Особенности получения профес- } \\
\text { сионального образования }\end{array}$ & Фокус деятельности & $\begin{array}{c}\text { Страны, реализующие } \\
\text { такой тип модели }\end{array}$ \\
\hline $\begin{array}{l}\text { Тип 1: «архитектор-пла- } \\
\text { нировщик» }\end{array}$ & Архитектурные факультеты & $\begin{array}{l}\text { «ОБЪЕКТ»: физическое преобра- } \\
\text { зование городской среды, благо- } \\
\text { устройство }\end{array}$ & $\begin{array}{l}\text { Республика Армения, } \\
\text { Республика Молдова, } \\
\text { Словакия, Венгрия }\end{array}$ \\
\hline $\begin{array}{l}\text { Тип 2: «градостроитель } \\
\text { с определённой специ- } \\
\text { ализацией» }\end{array}$ & $\begin{array}{l}\text { Архитектурно-градостроительные } \\
\text { факультеты университетов, универ- } \\
\text { ситетская образовательная средая }\end{array}$ & $\begin{array}{l}\text { «СТИ»: инфраструктурные проек- } \\
\text { ты; транспортно-сетевые решения }\end{array}$ & $\begin{array}{l}\text { Республика } \\
\text { Белоруссия; Латвия; } \\
\text { Литва }\end{array}$ \\
\hline $\begin{array}{l}\text { Тип 3: «градостроитель» } \\
\text { (в виде отдельной про- } \\
\text { фессии) }\end{array}$ & $\begin{array}{l}\text { Специализированные архитектур- } \\
\text { но-строительные вузы }\end{array}$ & $\begin{array}{l}\text { «ПРОЕКТ»: обеспечение докумен- } \\
\text { тальной базы для пространственных } \\
\text { инициатив государства, бизнеса, } \\
\text { инвестиционных проектов }\end{array}$ & Po \\
\hline $\begin{array}{l}\text { Тип 4: «профессионал» } \\
\text { с градостроительной } \\
\text { специализацией }\end{array}$ & $\begin{array}{l}\text { Архитектурные и градостроитель- } \\
\text { ные факультеты, инновационная } \\
\text { образовательная среда }\end{array}$ & $\begin{array}{l}\text { «ПРОЦЕССЫ»: обеспечение само- } \\
\text { организации процессов развития, } \\
\text { совместное планирование }\end{array}$ & $\begin{array}{l}\text { Польша, Сербия, } \\
\text { Эстония }\end{array}$ \\
\hline
\end{tabular}


ние городской застройки; преимущественно ориентируется на эстетические аспекты формирования среды; ассоциируется с социалистической моделью специалиста в области градостроительства.

- Тип 2: «градостроитель с определённой специализацией» (градостроитель-проектировщик транспортных коммуникаций): «инженер», подготовленный для решения широкого спектра технологических, проектных, расчётно-аналитических задач; ориентирован на развитие инфраструктур.

- Тип 3: «градостроитель» (в виде отдельной профессии): задумывался как специалист по комплексной организации процесса градостроительного преобразования пространства; имеет навыки архитектурного проектирования и инженерных расчётов. Обычно является частью архитектурной специализации; в мировой практике в таком виде постепенно исчезает.

- Тип 4: «профессионал с градостроительной специализацией» - может иметь базовое образование разного типа; эта модель реализуется посредством различных магистерскихпрограмм; проблемный аспект - удалённость от навыков проектирования, недостатокхудожественной и творческой подготовки.

Постсоветское прошлое служит своеобразной точкой отсчёта ${ }^{7}$, когда мы всматриваемся в современные институты профессии градостроителя. Часть из них (в Польше, Эстонии, Латвии) дают своему социалистическому опыту строго негативную оценку. Три последних десятилетия фокус их градостроительства направлен на усиление социальной компоненты и налаживание условий для партисипатизации. В качестве основы они используют организованные ещё в эпоху СССР учебные заведения, но модель специалиста выстроена согласно с общемировыми представлениями о ключевых ${ }^{8}$ навыках в градостроительстве. Специфический вектор развития профессионального градостроительного мышления задаётся установкой на проблематику «перекодирования социалистического наследия» в городах и ландшафтах [8], устранение противоречий, возникших на фоне приватизационных процессов и жилищной политики конца XX века. Профессиональное сообщество Сербии транслирует нейтральный тон в отношении социалистического наследства [7; 1], но активно содействует актуализации образовательных и исследовательских процессов.

Другие страны (Беларусь, Молдова), ссылаются на социалистический опыт как на положительный, озвучивая идеи его сохранения или незначительных преобразований. Профессиональное сообщество этих стран рассматривает «архитектуру и градостроительство как творческую деятельность, направленную на создание не только удобной и здоровой, но и эстетически совершенной среды обитания» [9]. Дуализм (между официальной градостроительной по- литикой, рассматривающей отрасль в творческом ключе, и общественными инициативами, которые ожидают встретить в градостроителе партнёра для обсуждения приемлемых организационных и пространственных решений) способствует приходу на образовательный рынок (в Молдову, Армению, Киргизию) западных учебных заведений, которые привносят собственные представления о градостроительстве и его роли.

Зарождающиеся институты «городского коучинга», «профессионального наставничества», «городского администрирования» становятся новыми полноправными элементами градостроительной отрасли Латвии, Сербии, Польши. А новые процедуры, связанные с совместным планированием, расширяют инструментарий деятельности. Рост числа участников и усложнение самих процедур приводит к необходимости смотреть на градостроительство значительно шире. Профессия и её институт становятся только частью экосистемы градостроительства ${ }^{9}$. Любая инициатива в области улучшений среды обитания подвергается многократным интерпретациям,

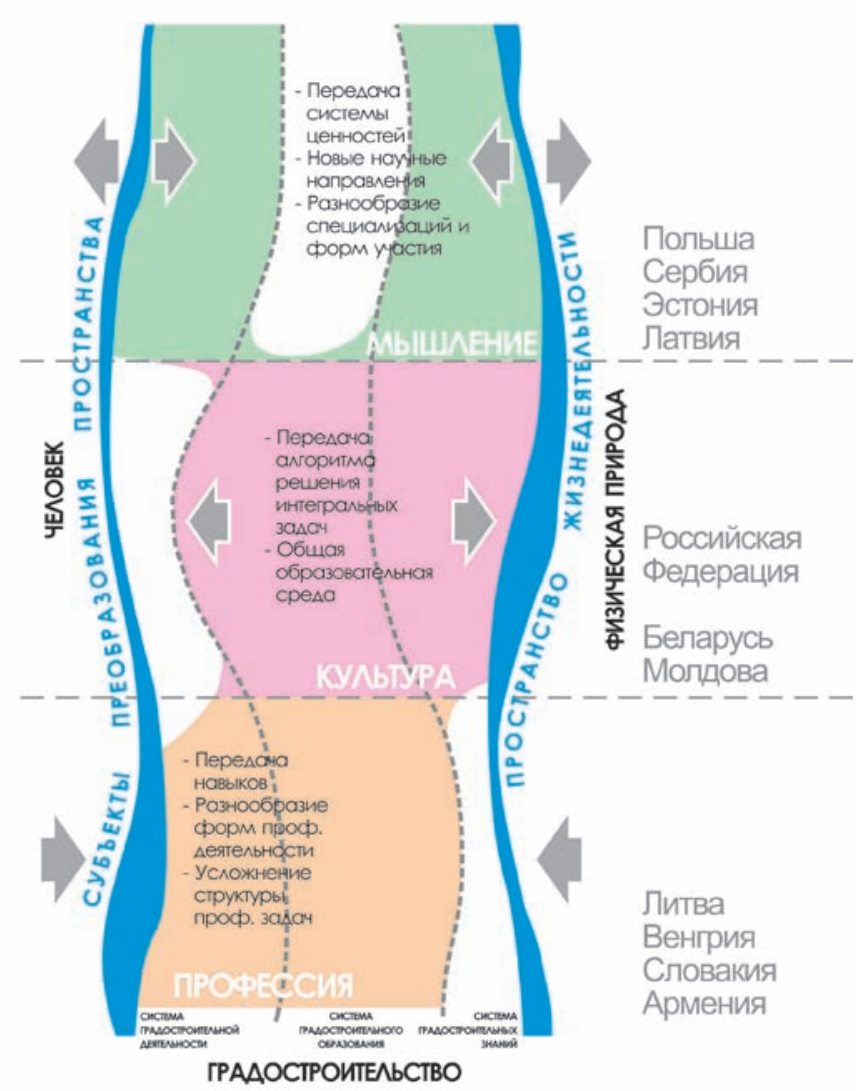

Pис. 1. Экосистема градостроительства и вариации её развития на постсоциалистическом пространстве. Автор схемы Н.Н. Жеблиенок

\footnotetext{
${ }^{7}$ В работе [8] отмечается, что «концепция постсоциалистического становится своеобразным контейнером для описания весьма неоднородных явлений».

${ }^{8}$ K таковым наиболее часто относят: междисциплинарная работа, совместное решение проблем, концептуальное мышление, навыки предвидения, стратегическое мышление, общение и разрешение конфликтов, этическое мышление, творческое видение, управление проектами, лидерство и управление заинтересованными сторонами.
} 
после чего - в форме системы точечных многоуровневых воздействий - реализуется в пространстве. Понимание особенностей работы экосистемы деятельности, её структуры и потенциала становятся, таким образом, новым фундаментальным навыком, определяющим принадлежность к институту профессионального градостроительства.

Экосистемы градостроительства, которые развиваются в постсоциалистических странах, объединяет уход от узко-отраслевого понимания градостроительства (рис. 1). Градостроительные сообщества исследуемых стран единодушны в стремлении развивать воспитательные, просвещенческие, внепрофессиональные инициативы и видеть в градостроительстве гуманитарный потенциал. Реализация этих амбиций существенно различается, поскольку связана с политическими, экономическими, национальными мотивами; всего может быть выделено три принципа в организации экосистем градостроительства: «профессиональный», «культурно-ориентированный» и «мировоззренчески-ориентированный».

Результаты проведённого исследования носят открытый дискуссионный характер и претендуют только на роль информации для профессиональных размышлений:

1) имеет место пугающая диспропорция между тем, как исследован институт профессии России и соседних с нею стран в отечественной и англоязычной науке. Тот факт, что российское градостроительство с трудом признаёт своё существование вне института деятельности, приводит к отставанию в количестве/качестве/уровне осмысления опыта мировой и собственной профессиональной культуры. Англоязычные отчёты и тексты обновляются фактически ежегодно. Но мы осведомлены о происходящем с российским градостроительством (и уж тем более - о происходящем с другими странами) значительно хуже, чем зарубежные исследователи;

2) сохранение глубоких содержательных связей между архитектурной и градостроительной деятельностью не означает, что сложившиеся системы образования подлежат консервации. Идеалы латинского направления в развитии градостроительства ещё сильны, тотальное разделение архитектуры и градостроительства не является единственным и неизбежным путём развития. Опыт Эстонии, Сербии, Польши показывает нам, что такая приверженность может сочетаться с глубокими и свежими взглядами на архитектуру и её ценности. Именно архитектурные факультеты становятся основой новейших методических разработок в градостроительной педагогике этих стран;

3) институты профессионального градостроительства постсоциалистических стран сохраняют много общего, однако при более широком взгляде на градостроительство каждой страны становится понятно, что основные векторы развития сегодня находятся вне плоскости профессии. «Профессия» как институт обладает огромной инерцией - и эти институты, сохраняя связь с архитектурой и строительной отраслью, всё ещё очень схожи на всём постсоциалистическом пространстве. Но традиционное понимание градостроительства (ограниченное «профессиональной деятельностью», «объектами профессионального образования» и субъектами, имеющими определённую квалификацию) не позволяет увидеть весь объём изменений, происходящий с отраслью. Основные отличия связаны с тем, как выстроен контакт с внепрофессиональными инициативами, реализуются функции планирования как коммуникационного процесса;

4) растущие объёмы новых научных направлений, усиление культурной составляющей в развитии градостроительства обуславливает переход от профессионально-отраслевой трактовки градостроительства к представлению о нём как об экосистеме. Прямая связь между главным действующим лицом градостроительной отрасли (как бы он не определялся нами) и объектом приложения его усилий (с той же долей условности назовем его «городом») фактически утеряна: целенаправленные воздействия не возможны ввиду количества заинтересованных лиц и разнообразия вариантов решений. Объект и субъект помещены в некоторую оболочку, которая является источником целей для преобразований и инструментом их реализации. В современном мире градостроительство выступает в роли такого рода оболочки, вмещающей в себя разные уровни и формы деятельности, разные типы участия и целый комплекс ролевых моделей;

5) постсоциалистическое пространство представлено очень схожими институтами профессии и крайне разнообразными экосистемами градостроительства. Отсутствие универсальности в данном случае - важнейшая черта современности. Жизнеспособность и устойчивость достигаются за счёт применения различных форм организации градостроительства, разных моделей для её главных действующих лиц. «Архитектор-планировщик», «градостроитель-проектировщик» или даже «консультант по инфраструктурному урбанизму»? Каждый из этих архетипов - центральный персонаж отрасли, он реализует общественные ожидания, решает градостроительные задачи в соответствии со спецификой региона и культурного контекста, в который помещён.

Показательно, что все страны сосредотачивают своё внимание на формировании экосистем градостроительства больше, чем на совершенствовании института профессии. Передача градостроительных навыков и знаний становится, скорее, образованием профильным, нежели профессиональным. И при разных вариантах: будь это планировочный профиль архитектора или градостроительный профиль эколога, важную роль начинает играть специализированная образовательная среда, поощряющая совместные коммуникации между обучающимися разных специальностей ${ }^{10}$ и местным

\footnotetext{
${ }^{9}$ Многие исследователи высказывают сомнения, что институт профессии в том виде, который нам известен, сохранит свою роль в градостроительстве XXI века. Например, «Urban Planners as Network Managers and Metagovernors» (англ. - градостроители как сетевые менеджеры или мета-управленцы), см. https://www.researchgate.net/publication/249016487_Urban_Planners_as_Network_Managers_and_Metagovernors.

${ }^{10}$ Характерно применение понятия «boundary crossing competence development» (англ. - развитие навыков пересечения границ) [10].
} 
сообществом [10]. Намечается тенденция к «снижению входного порога», то есть к отказу от творческих испытаний, вместо них всё чаще предлагается предоставить комплект проводимых самостоятельно городских исследований; расширяется круг распространения градостроительных знаний, теперь курсы по городским исследования и планированию ведутся на естественнонаучных, экологических, гуманитарных факультетах.

Тридцать лет назад постсоциалистические страны оказались лицом к лицу с масштабным кризисом градостроительного мировоззрения. До сих пор для мировой науки «постсоциалистическое градостроительство» часто ассоциируется с устаревшими формулами профессиональной деятельности разной степени непригодности. Но от пристального внимания не может скрыться уникальность происходящего: ведь нами, как и нашими соседями, сегодня тестируются совершенно новые интерпретации градостроительства. За короткий срок переформатированы профессии, оптимизированы работающие системы образования, полностью переписаны установки профессиональной культуры. Есть все основания полагать, что время, когда градостроительству с приставкой «постсоциалистическое» приходилось доказывать свое соответствие мировым трендам уже позади ${ }^{11}$. Получившиеся экосистемы градостроительства поражают своим разнообразием. Их нетрафаретность, возможно, и есть главная ценность. Напоминая нам о призрачном родстве в прошлом, она утверждает новый потенциал взаимодействий и совместной работы в будущем.

\section{Лumepamypa}

1. Maruna, M. Remodelling urban planning education for sustainable development: the case of Serbia [Электронный реcypc] / M Maruna, D. Milovanovic Rodic, R Colic // International Journal of Sustainability in Higher Education. - 2018. - Vol. 19. - №. 4. - Р. 658-680. - Режим доступа: https://www.emerald. com/insight/content/doi/10.1108/IJSHE-07-2017-0102/ full/html (дата обращения 06.12.2021). D0I: https://doi. org/10.1108/IJSHE-07-2017-0102.

2. Rembarz, G. Teaching infrastructure urbanism to aid participatory [Электронный ресурс] / G. Rembarz, J. MartyniukPęczek // Researchgate. - Режим доступа: (2019) https:// www.researchgate.net/publication/338216040_Teaching _ infrastructure_urbanism_to_aid_participatory_planning (дата обращения 18.11.2021).

3. Teaching ethics for urban planners and architects [Электронный ресурс] / T. Kuczynski, A. Kuczynska //

\footnotetext{
${ }^{11}$ Тридцатилетний период становления институтов градостроительства на постсоциалистическом пространстве, действительно, позволяет сменить оценочный тон (успевают ли? соответствуют ли передовым моделям развития отрасли?) на более серьёзную аналитику. Мы стоим на пороге этапа, когда постсоциалистические профессиональные сообщества, первыми пройдя в жёстком кризисном режиме процедуры существенного обновления в условия XXI века, смогут диктовать новые тенденции и выстраивать собственную градостроительную повестку дня. За одного битого, как известно...
}

Researchgate. - Режим доступа: https://www.researchgate. net/publication/228702432_TEACHING_ETHICS_FOR_URBAN_ PLANNERS_AND_ARCHITECTS (дата обращения 10.11.2021)

4. Czekiel-Świtalska, E. The urban planner profession and professional practice in Poland [Электронный ресурс] / CzekielŚwitalska E. // Researchgate. - Режим доступа: https:// www.researchgate.net/publication/304461858_THE_URBAN_ PLANNER_PROFESSION_AND_PROFESSIONAL_PRACTICE_IN_ POLAND (дата обращения 11.11.2021).

5. Kafka, K. Urban Planners in Poland. Practicing the Urban Planning Profession in Poland and Other European Countries [Электронный ресурс] / K. Kafka // Technical Transactions. 2018. - Vol.115. - № . - Р. 39-51. - Режим доступа: https:// www.researchgate.net/publication/340949205_Urban_ Planners_in_Poland_Practicing_the_urban_planning_ profession_in_Poland_and_other_European_countries_ Urbanista_w_Polsce_Wykonywanie_zawodu_urbanisty_i_ planisty_przestrzennego_w_Polsce_i_innych_kra (дата обращения10.11.2021). DOI: https://doi.org/10.4467/235373 7ХCT.18.071.8553.

6. Rembarz G. The Urban Mentoring as a New Method of Participatory Urban Planning in Poland [Электронный ресурс] / G. Rembarz J. Martyniuk-Pęczek // Researchgate. - Режим доступа: https://www.researchgate.net/publication/309280366_ The_Urban_Mentoring_as_a_New_Method_of_Participatory_ Urban_Planning_in_Poland (дата обращения 16.11.2021).

7. Čolić, N. Beyond formality: A contribution towards revising the participatory planning practice in Serbia [Электронный ресурс] / N. Čolić, 0. Dželebdžić // Researchgate. - Режим доступа: https://www.researchgate.net/publication/327934005_ Beyond_formality_A_contribution_towards_revising_the participatory_planning_practice_in_Serbia (дата обращения 11.12.2021).

8. Ilchenko, M. Editorial: In Search of the Post-Socialist Urban Geography. How Do We See the Post-Socialist City Today? [Электронный ресурс] / M Ilchenko, D. Dushkova // Researchgate. - Режим доступа: https://www.researchgate. net/publication/332901845_Editorial_In_search_of_the_postsocialist_urban_geography_How_do_we_see_the_postsocialist_city_today (дата обращения 10.11.2021).

9. Потаев, Г.А. Семь правил создания красивых городов [Электронный ресурс] / Г.А. Потаев // Белорусский союз архитекторов. Официальный сайт. - Режим доступа: http:// www.bsa.by/news/BUA/sem-pravil-sozdaniya-krasivyihgorodov (дата обращения 25.11.2021).

10. Oonk, C. Educating collaborative planners: strengthening evidence for the learning potential of multi-stakeholder regional learning environments (2016) [Электронный ресурс] / C. Oonk // Researchgate. - Режим доступа: https:// www.researchgate.net/publication/308333698_Educating_ collaborative_planners_strengthening_evidence_for_the_ learning_potential_of_multi-stakeholder_regional_learning environments (дата обращения 17.11.2021) 


\section{References}

1. Maruna, M., Milovanovic Rodic, D. and Colic, R. Remodelling urban planning education for sustainable development: the case of Serbia. In: International Journal of Sustainability in Higher Education, Vol. 19, no. 4, pp. 658-680. Access mode: https://www.emerald.com/insight/content/doi/10.1108/ IJSHE-07-2017-0102/full/html (Accessed 12/06/2021). DOI: https://doi.org/10.1108/IJSHE-07-2017-0102. (In Engl.)

2. Rembarz G., Martyniuk-Pęczek J. Teaching infrastructure urbanism to aid participatory planning. Researchgate, 2019. Access mode: https://www.researchgate.net/publication/338216040_ Teaching_infrastructure_urbanism_to_aid_participatory_ planning (Accessed 11/18/2021). (In Engl.)

3. Kuczynski T., Kuczynska A. Teaching ethics for urban planners and architects/Researchgate, 2007. Access mode: https://www.researchgate.net/publication/228702432 TEACHING_ETHICS_FOR_URBAN_PLANNERS_AND_ARCHITECTS (Accessed 11/10/2021). (In Engl.)

4. E. Czekiel-Świtalska The urban planner profession and professional practice in Poland. Researchgate, 2016. Access mode: https://www.researchgate.net/publication/304461858_ THE_URBAN_PLANNER_PROFESSION_AND_PROFESSIONAL_ PRACTICE_IN_POLAND (Accessed 11/11/2021). (In Engl.)

5. Kafka K. Urban Planners in Poland. Practicing the Urban Planning Profession in Poland and Other European Countries. In: Technical Transactions, 2018, vol. 115, no. 5, pp. 39-51. Access mode: https://www.researchgate.net/publication/340949205_Urban_ Planners_in_Poland_Practicing_the_urban_planning_profession_ in_Poland_and_other_European_countries_Urbanista_w_Polsce_ Wykonywanie_zawodu_urbanisty_i_planisty_przestrzennego_w_ Polsce_i_innych_kra (Accessed 11/10/2021). D0I: https://doi.org /10.4467/2353737XCT.18.071.8553. (In Engl.)
6. Rembarz G., Martyniuk-Pęczek J. The Urban Mentoring as a New Method of Participatory Urban Planning in Poland. Researchgate, 2016. Access mode: https://www.researchgate. net/publication/309280366_The_Urban_Mentoring_as_a_ New_Method_of_Participatory_Urban_Planning_in_Poland (Accessed 11/16/2021).

7. Čolić N., Dželebdžić 0 . Beyond formality: A contribution towards revising the participatory planning practice in Serbia. Researchgate, 2018. Access mode: https://www.researchgate. net/publication/327934005_Beyond_formality_A_ contribution_towards_revising_the_participatory_planning_ practice_in_Serbia (Accessed 12/11/2021). (In Engl.)

8. Ilchenko M., Dushkova D. Editorial: In Search of the PostSocialist Urban Geography. How Do We See the Post-Socialist City Today? Researchgate, 2018. Access mode: https://www. researchgate.net/publication/332901845_Editorial_In_search_ of_the_post-socialist_urban_geography_How_do_we_see_the post-socialist_city_today (Accessed 11/10/2021). (In Engl.)

9. Potaev, G.A. Sem' pravil sozdaniya krasivykh gorodov [Seven rules for creating beautiful cities]. In: Belorusskii soyuz arkhitektorov. Ofitsial'nyi sait [Belarusian Union of Architects. Official site]. - Access mode: http://www.bsa.by/ news/BUA/sem-pravil-sozdaniya-krasivyih-gorodov (Accessed 11/25/2021). (In Russ.)

10. OonkC. Educating collaborative planners: strengthening evidence for thelearning potential of multi-stakeholder regional learning environments. Researchgate, 2016. Access mode: https://www.researchgate.net/publication/308333698_ Educating_collaborative_planners_strengthening_evidence_ for_the_learning_potential_of_multi-stakeholder_regional_ learning_environments (Accessed 11/17/2021). (In Engl.) 